\title{
Optical Illusions Quintuple during Laparoscopic Total Extraperitoneal Preperitoneal (TEPP) TEPP Hernioplasty - Case Report 2
}

\author{
Maulana M Ansari* \\ Department of Surgery, Jawaharlal Nehru Medical College Hospital, Aligarh Muslim University, India
}

Submission: August 13, 2018; Published: September 24, 2018

*Corresponding author: Maulana Mohammed Ansari, Ex-Professor of General Surgery, Department of Surgery, Jawaharlal Nehru Medical College Hospital, Aligarh Muslim University, B-27 Silver Oak Avenue, Street No. 4 End, Dhaurra Mafi, Aligarh, Up, India- 202001, Tel: 0091-9557449212; Email: mmansari.amu@gmail.com

\section{Abstract}

Anatomical illusion during non-biliary surgery has not been reported in English literature except for the recent reports by the author [1]. Bilateral laparoscopic total extraperitoneal preperitoneal (TEPP) hernioplasty was performed in a healthy 45-year old man through posterior rectus sheath approach with 3-midline-port technique and direct telescopic dissection in the posterior rectus canal. On right side, five optical illusions were transiently experienced, viz., rectusial fascia vs. transversalis fascia, primary vs. secondary arcuate line, incomplete vs. complete posterior rectus sheath, lower attenuated part of complete posterior rectus sheath vs. transversalis fascia, superficial layer of double-layered preperitoneal fascia vs. transversalis fascia. Procedure was completed in 2 hours with significant technical difficulties. Simultaneous left TEPP hernioplasty was performed with ease and safety in 45 minutes despite presence of contralateral non-mirror anatomy.

Keywords: Laparoscopic hernioplasty; TEPP/ TEP; Optical illusion; Anatomical illusion, Secondary arcuate line; Primary arcuate line; Arcuate line; Posterior rectus sheath; Preperitoneal fascia; Transversalis fascia

Abbreviations: TEPP/ TEP: Total Extraperitoneal Preperitoneal (Hernioplasty); PRS: Posterior Rectus Canal; C-PRS: Complete Posterior Rectus Sheath; IC-PRS: Incomplete Posterior Rectus Sheath

\section{Introduction}

Optical illusion of biliary anatomy is now a well-known human factor for increased incidence of laparoscopic bile duct injury [2]. Anatomical illusion during non-biliary surgery has not been reported in literature to the best of our knowledge except

for a recent report by the author [1,3]. The author experienced a total of five transient optical illusions during laparoscopic total extraperitoneal preperitoneal (TEPP) hernioplasty in two adult male patients with primary inguinal hernia, and details of one case are presented herein.

Case Report
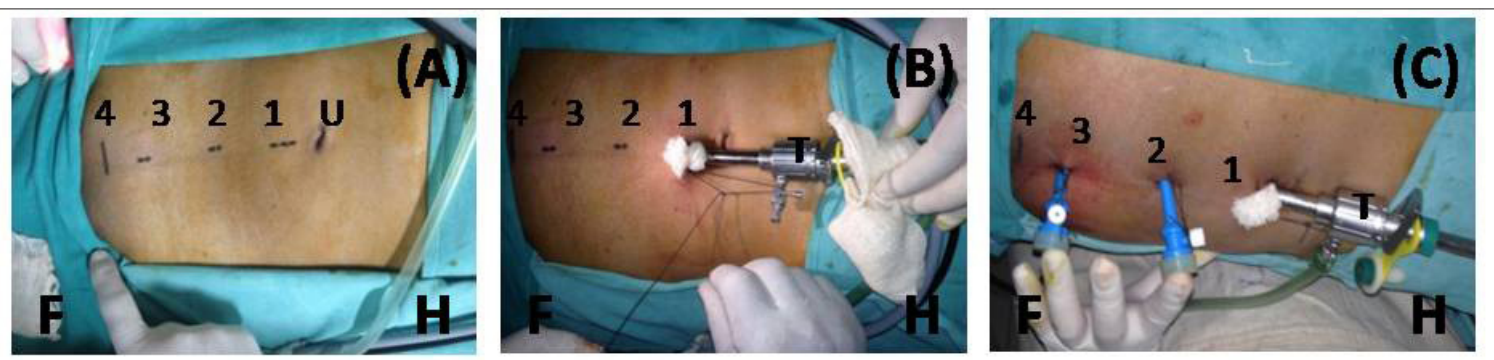

Figure 1: Port Placement for Laparoscopic Total Extraperitoneal Preperitoneal (TEPP) Hernioplasty for Inguinal Hernia; F: foot end of patient; $\mathrm{H}$ : head end of patient; $\mathrm{U}$ : umbilicus; 1: infraumbilical site for camera port (11mm); 2 \& 3: sites for working ports (5mm); 4: upper border of pubic symphysis; T: $11 \mathrm{~mm}$ metallic trocar with $10 \mathrm{~mm} 0^{0}$ telescope in-situ; Blue trocars: 5 -mm plastic trocars; (Reproduced with permission from Ansari MM. A Study of Laparoscopic Surgical Anatomy of Infraumbilical Posterior Rectus Sheath, Fascia Transversalis \& Pre-Peritoneal Fat/Fascia during TEPP Mesh Hernioplasty for Inguinal Hernia. -Doctoral Thesis for PhD (Surgery), Aligarh Muslim University, Aligarh, India, 2016). 


\section{Juniper Online Journal of Case Studies}
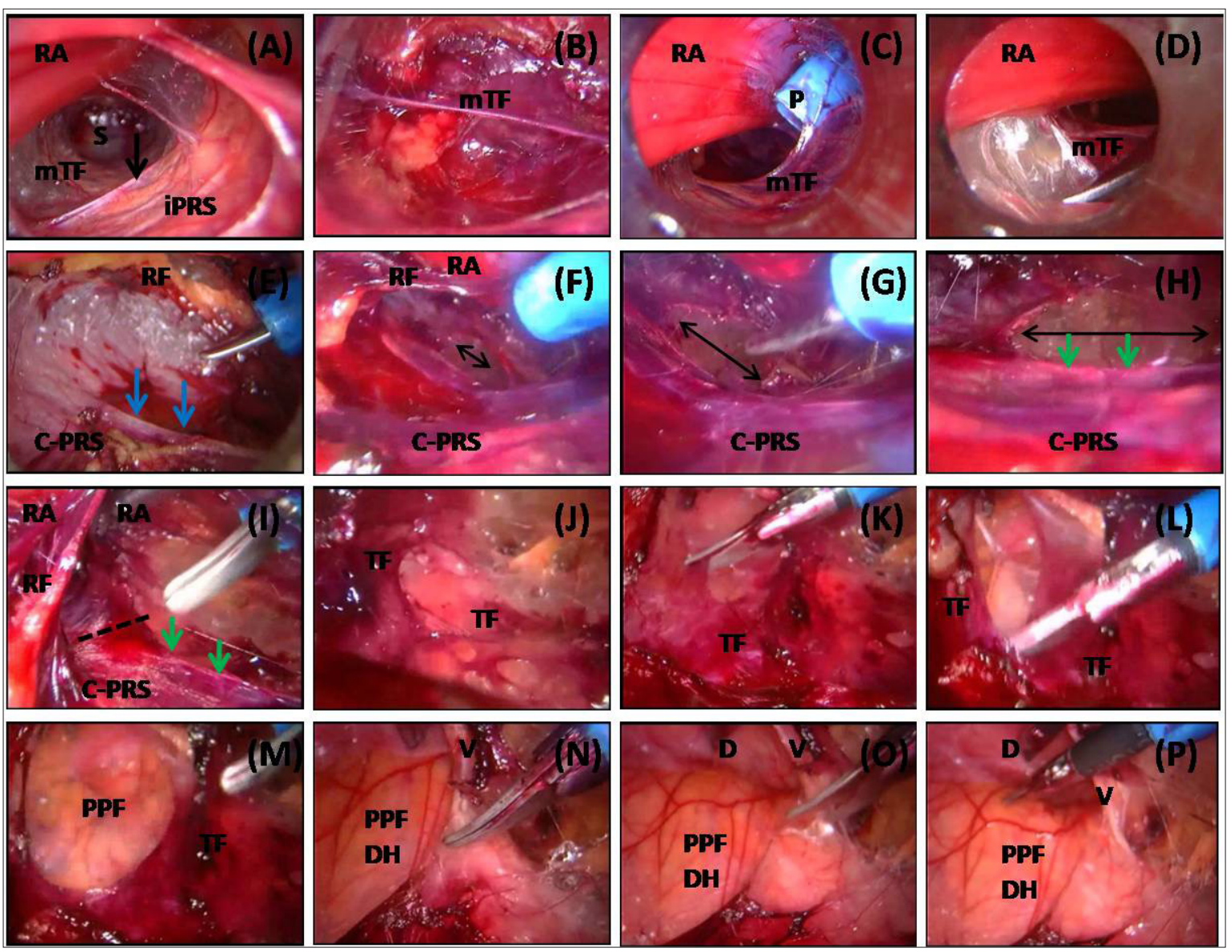

Figure 2: Multiple Anatomic Illusions $(n=5)$ during Right Laparoscopic Total Extraperitoneal Preperitoneal (TEPP) Hernioplasty in a Patient with Partly Tendinous Complete Posterior Rectus Sheath (C-PRS):

(A) Telescopic Dissection in true retro-rectus plane bounded anteriorly by rectus abdominis muscle (RA) and posteriorly by an apparently classical incomplete posterior rectus sheath (IPRS) having a classical primary arcuate line (Black Arrow) in upper part and apparently transversalis fascia (MTF) in lower part; (B) Misidentified transversalis fascia (MTF) perforated with telescope below misidentified primary arcuate line;

(C) First middle working port $(P)$ put in;

(D) Blunt/sharp instrument dissection underneath the misidentified transversalis fascia;

(E-F) True posterior rectus canal was found bounded posteriorly by attenuated C-PRS continuing up to pubic bone and containing a secondary arcuate line (Blue Arrow) which was initially misidentified as primary arcuate line (IIlusion 1); upper tendinous part of C-PRS misidentified initially as the classical incomplete posterior rectus sheath (Illusion 2) and lower attenuated part of C-PRS below arcuate line misidentified initially as transversalis fascia; Ansari's rectusial fascia forming anterior boundary of posterior rectus canal was misidentified initially as transversalis fascia (IIlusion 4);

(G-H) Making a transverse opening (Double-headed Black Arrow) in the attenuated complete posterior rectus sheath (C-PRS), i.e. creation of an artificial arcuate line (Green Arrow);

(I) Extension of artificial arcuate line (Dashed Line); tendinous nature of posterior rectus sheath clearly visible here

(J) Thin membranous transversalis fascia (TF) visible underneath C-PRS and torn at places due to CO2-pressure effect and handling;

(K) Division of transversalis fascia;

(L) Dissection of transversalis fascia (TF) to reach preperitoneal space;

(M) Preperitoneal fascia covering preperitoneal fat visible through rent in transversalis fascia; preperitoneal fascia misidentified initially as the posterior lamina of transversalis fascia (Illusion 5);

$(\mathrm{N}-\mathrm{P})$ Dissection in preperitoneal space between transversalis fascia (TF) and preperitoneal fascia (PPF) and reduction of direct inguinal hernia (DH) along with its covering of preperitoneal fascia (PPF); S: sign of lighthouse faintly visible; D: Direct hernial defect with in-situ pseudosac formed by transversalis fascia (TF); V: deep inferior epigastric vessels; (Reproduced with permission from Ansari MM. A Study of Laparoscopic Surgical Anatomy of Infraumbilical Posterior Rectus Sheath, Fascia Transversalis \& Pre-Peritoneal Fat/Fascia during TEPP Mesh Hernioplasty for Inguinal Hernia. -Doctoral Thesis for PhD (Surgery), Aligarh Muslim University, Aligarh, India, 2016). 
A 45-year-old male labourer (RL \#12) with body mass index of $22.6 \mathrm{Kg} / \mathrm{m}^{2}$ and ASA grade I presented with bilateral inguinal hernia. Posterior rectus sheath approach was utilized with 3-midline-port technique for bilateral laparoscopic total extraperitoneal preperitoneal (TEPP) hernioplasty. Right side was operated first. Direct telescopic dissection was used to create initial space creation in the posterior rectus canal. On insertion of a $10 \mathrm{~mm} 0$ telescope into the posterior rectus canal, the immediate endoscopic view reflected a classical textbook picture as taught in our anatomy classrooms, i.e., the anterior boundary of the posterior rectus canal being formed by the rectus abdominis muscle and the posterior boundary being formed in its upper part by aponeurotic incomplete posterior rectus sheath with a welldefined sharp arcuate line and in its lower part by the transversalis fascia (Figure $1 \& 2 \mathrm{~A}$ ).

Further telescopic dissection in this retro-rectus dissection proved rather difficult and bloody due to tearing of tiny vessels supplying both the rectus abdominis muscle and the fascia forming the posterior wall of this plane; the telescopic tip was using to perforate the fascia below the apparent arcuate line, but the plane became a little bloody again (Figure 2B). So, the first working port was then put in, and the blunt/sharp instrument dissection soon rectified the misperception by revealing the presence of a partly tendinous complete posterior rectus sheath extending upto the pubic bone and containing an in-transit secondary arcuate line which was initially misidentified as the primary arcuate line (Illusion 1) (Figure 2C-2D). The upper aponeurotic part of the complete posterior rectus sheath above the secondary arcuate line was misidentified as the classical aponeurotic incomplete posterior rectus sheath (Illusion 2), and the well-defined fascial rectus epimysium called the 'Rectusial fascia of Ansari' [4] which was taken down on to the floor of the operating field was initially misidentified as the transversalis fascia (Illusion 3). The lower attenuated part of the complete posterior rectus sheath, i.e., the 'rectus sheath fascia of Arregui' [5] was momentarily misidentified as the transversalis fascia (Illusion 4) (Figure 2E). Application of the 'methods of error reduction' timely rectified the transient misperception, i.e., the posterior rectus sheath was continuous up to the pubic bone and contained, in addition to a tendinous band called secondary arcuate line, tendinous fibres lower down (Figure 2E-2I) which are never present in the transversalis fascia.

As the primary terminal arcuate line was absent, an artificial arcuate line as described earlier by the author [5-7] for an ergonomic access to the preperitoneal space was surgically created in the complete posterior rectus sheath at the level of the middle port (Figure $2 \mathrm{~F}-2 \mathrm{H}$ ) when two fascial layers was detected underneath it (Figure 2J-2K). These two fascial layers were initially perceived as the two lamina of a double-layered transversalis fascia in the first glance but further unhurried gentle dissection and application of 'methods of error reduction' revealed that the superficial thin membranous fascial layer was really the transversalis fascia proper which formed the pseudosac of the direct inguinal hernia and the deeper diaphanous fascial layer was the preperitoneal fascia/fat (Illusion 5) (Figure 2L$2 \mathrm{M}$ ). The superficial thin membranous fascial layer (transversalis fascia) was found readily separable in an avascular fashion from the deeper diaphanous layer (preperitoneal fascia/fat) which covered the direct hernial sac and got easily reduced with it into the abdomen (Figure 2N-2P).

The avascular plane between the transversalis fascia and the preperitoneal fascia, which was earlier reported as the 'surgical preperitoneal space' by the author $[9,10]$ was found easily extendable laterally into the 'surgical preperitoneal space' of the subinguinal space. These optical illusions resulted in significant surgical difficulties, leading to completion of the procedure in 2 hours.

During the contralateral TEPP repair on the left side in the same sitting, the anatomical disposition included welldefined rectusial fascia, incomplete posterior rectus sheath of partly tendinous nature, ill-defined primary arcuate line, single diaphanous transversalis fascia and single membranous preperitoneal fascia, and the procedure was completed smoothly and rapidly in 45 minutes.

\section{Discussion}

Primary anatomical outcome measures of our doctoral research study have been reported earlier by the author [10-12], re-emphasizing the surgical significance of the anatomic variations of inguinal anatomy sporadically reported in literature since long. Modern newer laparoscopic approaches of surgery offer excellent lighting, high magnification and internal perspective which provide clear visualization of even thinnest fascial layers and tissues not appreciated during gross anatomic dissections because of their hardening and fusion during the process of embalming. However, the laparoscopic environment facilitates occurrence of anatomical illusions, leading to intraoperative technical difficulties and complications, as documented in relation to the higher incidence of the bile duct injury during laparoscopic cholecystectomy by Way et al. [2] and Stewart \& Way [13]. However, the phenomenon of optical illusion has not been explored in the non-biliary surgery except for a recent report by the author [1]. Highly variable multifascial layers of inguinal anatomy are potentially prone to optical illusion, as highlighted by the present case. Lack of the knowledge of the older literature of the inguinal anatomy and their frequent variations [10-12] in the early part of our study of the TEPP hernioplasty was possibly responsible for our proneness to the optical illusion. Laparoscopic hernia surgeon who wishes to start TEPP repair is strongly advised first to go through the anatomic literature beyond the traditional textbooks of surgery and anatomy in order to familiarize him/ herself the frequent variations of abdomino-inguinal anatomy. Optical illusions during TEPP hernioplasty warrant for due cognizance for their potential occurrence to safeguard against the injudicious dissection/ technical difficulty for seamless execution of the procedure with ease, rapidity and safety. 
Non-mirror anatomy on contralateral side has been reported in a high percentage from $37.5 \%$ to $62.5 \%$ by the author $[11,12]$. However, experience of laparoscopic TEPP hernioplasty on one side may benefit the operator on the contralateral side although there may not be an exact mirror anatomy on the opposite side as was experienced in the present case.

\section{Conclusion}

A total of five optical illusions were documented during the procedure of laparoscopic TEPP hernioplasty in an adult patient with bilateral primary inguinal hernia. Significant surgical difficulties were experienced with prolongation of the operation time. Due cognizance of the potential optical illusion during TEPP hernioplasty is strongly recommended in order to pre-empt the injudicious dissection and technical difficulties for hassle-free performance with rapidity and safety.

\section{Acknowledgement}

The content of this article is taken with permission from collateral observations documented during the doctoral research thesis/dissertation for award of degree of PhD (Surgery) to the author for year 2016 by the Aligarh M. University, UP, India 202001.

\section{References}

1. Way LW, Stewart L, Gantert W, Liu K, Lee CM, et al. (2003) Causes and Prevention of Laparoscopic Bile Duct Injuries: Analysis of 252 Cases from a Human Factors and Cognitive Psychology Perspective. Ann Surg 237(4): 460-469.

2. Ansari MM (2018) Triple optical illusions during TEPP hernioplasty a case report. Clin Med Images Int J (In Press).

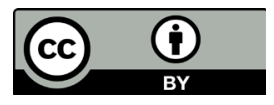

This work is licensed under Creative Commons Attribution 4.0 License DOI: 10.19080/JOJCS.2018.08.555745
3. Ansari MM (2018) Optical Illusions Quintuple during Laparoscopic Total Extraperitoneal Preperitoneal (TEPP) Hernioplasty - A Case Report. Int J Surg Sci 2(1): 33-36.

4. Ansari MM (2017) Rectusial Fascia: A New Entity of Laparoscopic Live Surgical Anatomy. Open Access J Surg 3(4): pp 1-5.

5. Arregui ME (1997) Surgical anatomy of the pre-peritoneal fasciae and posterior transversalis fasciae in the inguinal region. Hernia 1(2): 101110.

6. Ansari MM (2017) Artificial Arcuate Line: Surgical Creation during TEPP Hernioplasty. Clin Surg 2(1698): 2.

7. Ansari MM (2017) Arcuate Line Variations: Surgical Significance and Clinical Implications during TEPP Hernioplasty. J Surg Clin Interventions 1(1): 1-8.

8. Ansari MM (2018) Posterior rectus sheath variations: surgical significance and clinical implications for laparoscopic hernia surgeons. Int Surg J 5(2): 683-694.

9. Ansari MM (2018) Surgical preperitoneal space: holy plane of dissection between transversalis fascia and preperitoneal fascia for TEPP inguinal hernioplasty. MedCrave Online J Surg 6(2): 26-33.

10. Ansari MM (2017) Transversalis Fascia and Preperitoneal Fascia: A Laparoscopic Study of Live Surgical Anatomy during TEPP Hernioplasty-Final Report and Literature Review. Ann Int Med Dent Res 3(6): SG19-SG32.

11. Ansari MM (2018) Posterior Rectus Sheath: A Prospective Study of Laparoscopic Live Surgical Anatomy during TEPP Hernioplasty. World J Laparosc Surg 11(1): 1-13.

12. Ansari MM (2017) Arcuate Line of Douglas: A Prospective Study of Laparoscopic Live Surgical Anatomy during TEPP Hernioplasty. Int J Sci Res 6(6): 2348-2363.

13. Stewart L, Way LW (2007) The Prevention of Laparoscopic Bile Duct Injuries: an Analysis of 300 Cases of from a Human Factors and Cognitive Psychology Perspective. Proceedings of the Human Factors and Ergonomics Society 51 $1^{\text {st }}$ Annual Meeting 2007 51(11): 617-620.

\section{Your next submission with Juniper Publishers will reach you the below assets}

- Quality Editorial service

- Swift Peer Review

- Reprints availability

- E-prints Service

- Manuscript Podcast for convenient understanding

- Global attainment for your research

- Manuscript accessibility in different formats

( Pdf, E-pub, Full Text, Audio)

- Unceasing customer service

Track the below URL for one-step submission https://juniperpublishers.com/online-submission.php 